equilibria. But of course we recognize that a naming system based on discrete entities will make any sequence look like a discontinuous array, and the debate has properly focused on the statistics of measured morphological change, not on published compendia of names. The evidence for punctuated equilibria is morphological, not nomenclatural.

Once again, we are confronted with profoundly different ontological conceptualizations of what species are: Sheldon, following traditional palaeontological practice, sees a species as arbitrarily delineated segments of an evolving continuum. As Mayr ${ }^{11}$ has said, a relatively complete fossil record would prohibit facile discrimination of species so conceived. In contrast, we follow the other ontological thread Mayr ${ }^{11}$ sets out, seeing species as discrete reproductive communities. Like Simpson $^{12}$ and Wiley ${ }^{13}$, we have no trouble imagining such reproductive communites persisting for considerable segments of geological time as lineages. The resultant picture of species as spatiotemporally discrete and independent reproductive lineages derives from punctuated equilibria, and is fraught with further implications for evolutionary theory - including the debate over 'species selection'.

Maynard Smith ${ }^{2}$ goes far beyond the measured tones of Sheldon's report. He cites species selection as his principal evidence that punctuated equilibria is just another manifestation of such palaeontological mistrust. He defines species selection as a causal theory of the origin and modification of organismal adaptation. Naturally, he has no trouble dismissing such an absurd postulate, saying that "there never was much sense in the idea anyway". Of course it makes no sense - stated this way. Maynard Smith seems not to realize that this characterization of species selection is entirely of his own making. Where discussions of our own (and colleagues ${ }^{14-16}$ ), on species selection address patterns of organismal phenotypic evolution, our idea is that 'sorting'

1. Sheldon, P.R. Nature 330, 561-563 (1987)

2. Maynard Smith, J. Nature 330, 516(1987).

3. Eldredge, N. \& Gould, S.J. in Models in Paleobiology (ed. Schopf, T.J.M.) 82-115 (Freeman, San Francisco, 1972).

Gingerich, P.D. Nature 248, 107-109 (1974).

5. Lande, R. Evolution 30, 314-334 (1976).

6. Simpson, G.G. Tempo and Mode in Evolution (Columbia Univ. Press, New York, 1944).

7. Stanley, S.M. Proc. natn. Acad. Sci. U.S.A. 72, $646(1975)$

8. Hughes, C.P. Bull. Br. Mus. nat. Hist., Geol. 18, 39 (1969).

9. Hughes, C.P. Bull Br. Mus, nat. Hist., Geol. 20, 115 (1971).

10. Hughes, C.P. Bull. Br. Mus mat. Hist, Geol. 32, 109 (1979).

11. Mayr, E. Systematics and the Origin of Species (Columbia Mayr, E. Systematics and the
Univ. Press, New York, 1942)

12. Simpson, G.G. Principles of Animal Taxonomy (Columbia Univ. Press, New York. 1961)

13. Wiley, E.O. Syst. Zool. 27, 17-26 (1978)

14. Eldredge, N. Unfinished Synthesis (Oxford Univ. Press, New York, 1985).

15. Vrba, E.S. \& Eldredge, N. Paleobiology 10, 146-171 (1984).

16. Vrba, E.S. \& Gould, S.J. Paleobiology 12, 217-228 (1986).

17. Coope, G.R. A. Rev. Ecol. Syst. 10, 247-267 (1979).

18. Eldredge, N. \& Gould, S.J. Evol. Biol. 7, 303-308 (1974).

19. Vrba, E.S. S. Afr. J. Sci. 81, 229-236 (1985)

20. Futuyma, D.J. Am. Nat. 130, 465-473 (1987)

21. Lande, R. Paleobiology 12, 343-354 (1986)

22. Osbom, H.F. Am. Nat. 68, 193-235 (1934) of species changes the spectrum of genetically based phenotypes available for the ongoing populating of ecosystems - and for further events in the genealogical history of life.

Morphological adaptations are complex properties of organisms, and therefore presumably evolved directly at the level of organisms. But patterns of waxing and waning of diversity occur at the species level. The myopia of traditional thinking lies in the assumption that such issues of the species level extrapolate directly from adaptation at the organismic and population levels. But we do not believe that the world contains millions of species of beetles and only a handful of pogonophorans simply because beetles represent a successful adaptive design. Propensity for speciation and resistance to extinction must also be considered.

There are other faulty characterizations of punctuated equilibria in Maynard Smith's commentary. He repeats, for example, the canard that palaeontologists invoke only 'developmental constraints' as a source of stasis - rather than 'normalizing selection'. Yet it is palaeontologists ${ }^{17-19}$ more than any other cadre of evolutionary biologists who have realized that environmental change results in habitat shifting. Continued persistence with relatively little change will be the rule as long as organisms can continue to recognize suitable habitats - a point only recently appreciated by some nonpalaeontological evolutionary theorists $\mathrm{s}^{20,21}$.

Palaeontologists don't mistrust population geneticists. Years ago, Henry Fairfield Osborn ${ }^{22}$, taking exception to the genetically-based evolutionary theories of his day, saw fit to invent his own ("aristogenesis"). G.G. Simpson ${ }^{6}$ put an end to that nonsense, showing that there must be a single, all-encompassing causal theory of evolution - one that integrates the principles of physiological and population genetics with the patterns of actual evolutionary history. We all still seek a more accurate integration. If Darwin gave us a general, very powerful, understanding of the basic mechanism of stasis and modification of organismic adaptations, all evolutionary biologists still await a coherent statement of the context of such stasis and change: a deeper understanding of when, and how much, evolutionary change might be expected to occur. Punctuated equilibria poses the challenging and almost counter-intuitive link between change in the economic adaptations of organisms and the disruption of reproductive communities that is speciation. Some non-palaeontological evolutionary biologists (for example Futuyma ${ }^{20}$ ) are beginning to pursue this line of thought. We should realize, though, that we are all darwinians in our focus upon selective processes; but in taking the fundamental charge of science seriously, supporters of punctuated equilibria seek a deeper understanding than that already achieved.

Niles ELDREDGE

Department of Invertebrates,

American Museum of Natural History,

New York, New York 10024, USA

STEPHEN JAY GOULD

Museum of Comparative Zoology,

Harvard University, Cambridge,

Massachusetts 02138, USA

\section{Energy conversion by gravitational waves}

SIR-We have been studying some surprising properties of the paths of particles and light rays in the field of a plane gravitational wave of limited duration - a sandwich wave' ${ }^{1}$ (Penrose ${ }^{2}$ has pointed out some exotic properties of null cones in this context.) We have shown (manuscript in preparation) that a plane gravitational wave induces large relative accelerations in initially widely separated test particles. Particles which initially are arbitrarily far apart and at relative rest will be constrained to collide within a finite time which is independent of their initial separations.

Here we point out that if such particles are charged, the accelerations will constitute a mechanism for the conversion of gravitational energy into electromagnetic energy: in a plasma, the electrons and the positive charge carriers will be equally affected by the gravitational field. As, however, the electromagnetic radiative reaction will affect the electrons far more than it will affect the positive charge carriers, with their much greater mass/charge ratio, radiation from the positive and negative carriers will not cancel. Professor B. Schutz of University College Cardiff has pointed out that the mechanism of energy transfer cannot be efficient at frequencies below a critical frequency, at which the gravitational wavelength equals the typical interparticle spacing in the plasma. For astrophyscial plasmas this critical frequency is in the gigahertz region or higher.

The attenuation of high-frequency gravitational waves in a plasma may therefore be much greater than has hitherto been expected, and the resulting electromagnetic radiation may have distinctive observable characteristics. The details of the energy transfer mechanism, and the applicability of the plane wave approximation near to likely sources of gravitational waves, require further study.

Churchill College, Cambridge

H. BONDI

CB3 ODS, UK

F.A.E. PIRANI

Kings College, London WC2R $2 L S, U K$

1. Bondi, H., Pirani, F.A.E. \& Robinson, I. Proc. R. Soc A251, 519-533 (1959)

2. Penrose, R. Rev. mod. Phys. 37, 215-220 (1965). 